\title{
New biomarkers in the selection of patients for talcage of pleural cavity in the palliative therapy of malign pleural exudate
}

\author{
Petr Habal ${ }^{\mathrm{a}}$ Nedal Omran ${ }^{\mathrm{a}}$, James Chek ${ }^{\mathrm{a}}$, Jan Krejsek ${ }^{\mathrm{b}}$, Jiri Mandak ${ }^{\mathrm{a}}$
}

\begin{abstract}
Background. Chemical pleurodesis using videothoracoscopically applied powdered talc under general anaesthesia and selective pulmonary ventilation is the most effective method of palliative therapy for malign pleural exudate. Talc produces an intense systemic inflammatory reaction with the development of aseptic pleurisy. The result is obliteration of the pleural cavity provided there is an intense inflammatory reaction in the pleural cavity and good contact of both pleural leaves. The course of the adherence of pleural leaves can be followed using skiascopy. In routine practice, the course of local inflammatory markers is difficult to evaluate. Selection of suitable patients who will respond to this procedure is another principal obstacle of this surgical method.
\end{abstract}

Aim. To evaluate the course of local inflammatory changes in the pleural cavity following application of talc and to quantify their dynamics. Selection of specific biomarkers to predict the intensity of inflammation in the pleural exudate for targeted selection of patients suitable for talcage was the second aim of this study.

Materials and Methods. 114 patients were retrospectively divided into Group A $\left(\mathrm{N}_{1}=98\right)$ or patients without relapse and Group $B\left(\mathrm{~N}_{2}=16\right)$, patients with relapse of exudate formation. The need for repeated thoracic punctures or drainage over the course of a 12-month monitoring period was a criterion of treatment failure. Quantification of the effusion was performed by ultrasonic examination over a one year observational period at 3-monthly intervals. The concentration of soluble CD163 scavenger receptor and soluble Apo/Fas molecule was determined in exudate by ELISA.

Results. Soluble receptors in the 2 groups differed significantly. Group B showed higher sCD163 levels before talcage $\left(P_{0}=0.00024\right)$, faster dynamic decline in $2 \mathrm{~h}\left(P_{2}=0.0092\right)$ and in $24 \mathrm{~h}\left(P_{24}=0.0087\right)$. During monitoring, decrease in group B was statistically significant at $2 \mathrm{~h}\left(P_{2}=0.056\right)$ and at $24 \mathrm{hrs}\left(P_{24}=0.0066\right)$.

Conclusion. This pilot study showed that high values of SCD163 and sApo/Fas in the pleural exudate can predict treatment failure. Unsuitable candidates for this type of therapy couldbe selected in this way.

Key words: malignant pleural exudate, thoracoscopy, talc, sCD163, sApo/Fas

Received: June 2, 2014; Accepted with revision: January 19, 2015; Available online: February 10, 2015

http://dx.doi.org/10.5507/bp.2015.005

${ }^{a}$ Department of Cardiac Surgery, Faculty of Medicine in Hradec Kralove, Charles University in Prague and University Hospital in Hradec Kralove, Czech Republic

${ }^{b}$ Department of Clinical Immunology and Allergy, Faculty of Medicine in Hradec Kralove, Charles University in Prague and University Hospital in Hradec Kralove

Corresponding author: Jiri Mandak, e-mail:jiri.mandak@centrum.cz

\section{INTRODUCTION}

Malignant pleural exudate is formed in a pathologically modified space between the sheets of the parietal and visceral pleura. Its worldwide annual incidence is $0.06 \%$ (ref. ${ }^{1}$ ). Under physiological conditions there is a virtual space between the sheets of parietal and visceral pleura of 10-20 $\mu \mathrm{m}$ in width with a minimum amount of fluid that facilitates respiratory movements ${ }^{2}$. Overproduction is caused either by imbalance of transpleural pressure or by increased permeability of capillary endothelium with impairment of lymphatic drainage ${ }^{3}$. The most commonly used palliative therapy so far is the administration of talc using the thoracoscopic (VTS) method ${ }^{4}$. The principle is induction of aseptic pleuritis with pleurodesis and destruction of the interpleural space. The administration efficacy of the powder form of talc is almost $90 \%\left(\right.$ ref. $\left.^{5}\right)$. Sporadically, only general inflammatory responses of the body are evaluated ${ }^{6}$. Information on and objective evaluation of early local response to administration of a foreign substance are entirely missing 7 . Binding of the foreign substance to the receptors triggers a cascade of cytokine production by innate immunity cells (dendritic cells) which subsequently activate $\mathrm{T}$ and $\mathrm{B}$ lymphocytes ${ }^{8}$. Soluble CD163 (sCD163) is a scavenger receptor for haemoglobin. CD163 is a member of the scavenger receptor super family class B of the first subgroup. It is mapped to the region p13 on chromosome 12. Five different isoforms of CD163 have been described, which differ in the structure of their cytoplasmic domains and putative phosporylation sites. This scavenger receptor is expressed on cells of monocytes and macrophages lineage exclusively. CD163 immunological function is essentially homeostatic. It has anti-inflammatory effects and the dynamics of its changes indicate an inflammatory response. A vital function of CD163 is the clearance of hemoglobin in its cell-free form and participation in anti-inflammation in its soluble form, exhibiting cytokine-like functions. It is apparent from the foregoing that the CD163 scavenger receptor can be used as a biomarker in different diseases 
and as a valuable diagnostic parameter in the prognosis of many diseases especially inflammatory disorders and sepsis ${ }^{9}$. Apo/Fas (also known as CD95) belongs to the subgroup of the tumor necrosis factor receptor (TNF-R) family that contain an intra-cellular "death domain" and can trigger apoptosis. Studies with spontaneous mutant mice, gene-targeted mice and cells from human patients have shown that Apo/Fas plays critical roles in the immune system, in particular in the killing of pathogen infected target cells and the death of redundant, potentially noxious cells as well as autoreactive lymphocytes. It triggers cellular death and regulates the immune response. It removes excessive lymphocytes and prevents exaggerated reactions ${ }^{10}$. It is assumed that macrophages, the principal local innate immunity cell population, encounters the instilled talc particles. Talc particles are internalised by macrophages in several ways

\section{MATERIAL AND METHODS}

The group included 114 patients with recurrent malignant pleural exudate. Quantification of the volume of exudate was performed using the ultrasound (USG) method for one year. Following evaluation of the treatment results, the group was retrospectively divided into Group A $\left(\mathrm{N}_{1}=98\right)$, patients without relapse and Group B $\left(\mathrm{N}_{2}=16\right)$, patients with relapse of exudate. Ultrasound was used to quantify the amount of pleural effusion during the follow up period. A cut off value of $400 \mathrm{~mL}$ of pleural effusion was established to determine whether the procedure was successful or not.

Exudate was evacuated in fractions perioperatively under general anaesthesia. Observation of the pleural cavity was followed by biopsy of the parietal pleura and administration of $5 \mathrm{~g}$ of talc. Thoracic drain was removed with a drained amount $<150 \mathrm{~mL} / 24 \mathrm{~h}$. A volume of $5 \mathrm{~mL}$ of the pleural effusion was collected in a test tube with heparin by means of a BD Vacutainer ${ }^{\circledR}$ (BD (Becton, Dickinson and Company, USA) with commercially guaranteed defined heparinization. The samples were centrifuged and supernatants were stored, frozen at $-70{ }^{\circ} \mathrm{C}$. The concen- trations of sApo/Fas and sCD163 molecules were determined using ELISA kits.

\section{Statistical analysis}

Comparison between pleural effusion collection at the three intervals was assessed by paired t-tests or by Wilcoxon test according to the normality of the data. Categorical data were tested by the Fischer exact test. Statistical significance was set at $P=0.05$.

The study protocol was approved by the Ethics Committee of the University Hospital in Hradec Kralove and informed consent was obtained from all participants.

\section{RESULTS}

The group included 114 patients with malign pleural exudate of various origin, $61(53.5 \%)$ males and 53 (46.5\%) females, 98 (86\%) of patients (Group A) had no relapse. Treatment failure occurred in 16 (14\%) of patients (Group B). The aetiology of the exudate in relation to the underlying diagnosis is shown in Table 1. The age range patients in group A was $63.6 \pm 3.2$ years and in group B $67.8 \pm 2.4$ years. Demographic data are included in Table 2 . The mean duration of the surgery was $44 \pm 12$ minutes; the mean time of chest drainage was $5 \pm 2$ days. Duration of hospitalisation was $7 \pm 2$ days. Both groups had different volume of exudate on admission $\left(P_{A d}=0.0014\right)$. There were no statistically significant differences in residual volume of exudate at discharge $\left(P_{D}=0.121\right)$. Significant differences in volume were found from the first month for the entire duration of monitoring between groups $A$ and B $\left(P_{1-12}<0.001\right)$ - Figure 1. The dynamics of expression of soluble forms of the selected receptors was monitored. Concentrations of the sCD163 values were markedly higher in group B before talcage $\left(P_{0}<0.001\right)$, even after two hours $\left(P_{2}=0.028\right)$. No statistically significant difference was found after $24 \mathrm{~h}\left(P_{24}=0.100\right)$ (Fig. 2). Group B also showed higher sApo/Fas levels before talcage $\left(P_{0}=\right.$ 0.00064). During monitoring, decrease in the group B was statistically significant at $2 \mathrm{~h}\left(P_{2}=0.056\right)$ and at $24 \mathrm{~h}\left(P_{24}\right.$ $=0.0066)($ Fig. 3).

Table 1. Basic diagnoses $(\mathrm{N}=114)$.

\begin{tabular}{|c|c|c|c|}
\hline & Group A* & Group B* & $P$-value \\
\hline Age (year) & $63.6 \pm 3.2$ & $67.8 \pm 2.4$ & $<0.05$ \\
\hline BMI $\left(\mathrm{kg} \cdot \mathrm{m}^{-2}\right)$ & $27(23-29)$ & $26(24-30)$ & n.s. \\
\hline Thoracoscore ${ }^{* *}$ & $5.4(2.7-8.2)$ & $6.9(5.2-7.9)$ & $<0.05$ \\
\hline Carcinoma of lungs n (\%) & $29(29.6 \%)$ & $2(14.3 \%)$ & $<0.001$ \\
\hline Malignant mesothelioma $\mathrm{n}(\%)$ & $25(25.6 \%)$ & $8(50 \%)$ & $<0.001$ \\
\hline Lymphoma of lungs n (\%) & $2(5.1 \%)$ & 0 & $<0.001$ \\
\hline Metastases n (\%) & $39(39.8 \%)$ & $6(42.8 \%)$ & $<0.001$ \\
\hline - breast n (\%) & $-19(48 \%)$ & $-2(33.3 \%)$ & $<0.001$ \\
\hline - ovary n (\%) & $-12(30.8 \%)$ & $-4(66.6 \%)$ & $<0.01$ \\
\hline - GIT n (\%) & $-4(10.3 \%)$ & 0 & $<0.001$ \\
\hline - Grawitz n (\%) & $-2(5.1 \%)$ & 0 & $<0.001$ \\
\hline$\sum \mathrm{n}(\%)$ & $98(86 \%)$ & $16(14 \%)$ & $<0.001$ \\
\hline
\end{tabular}




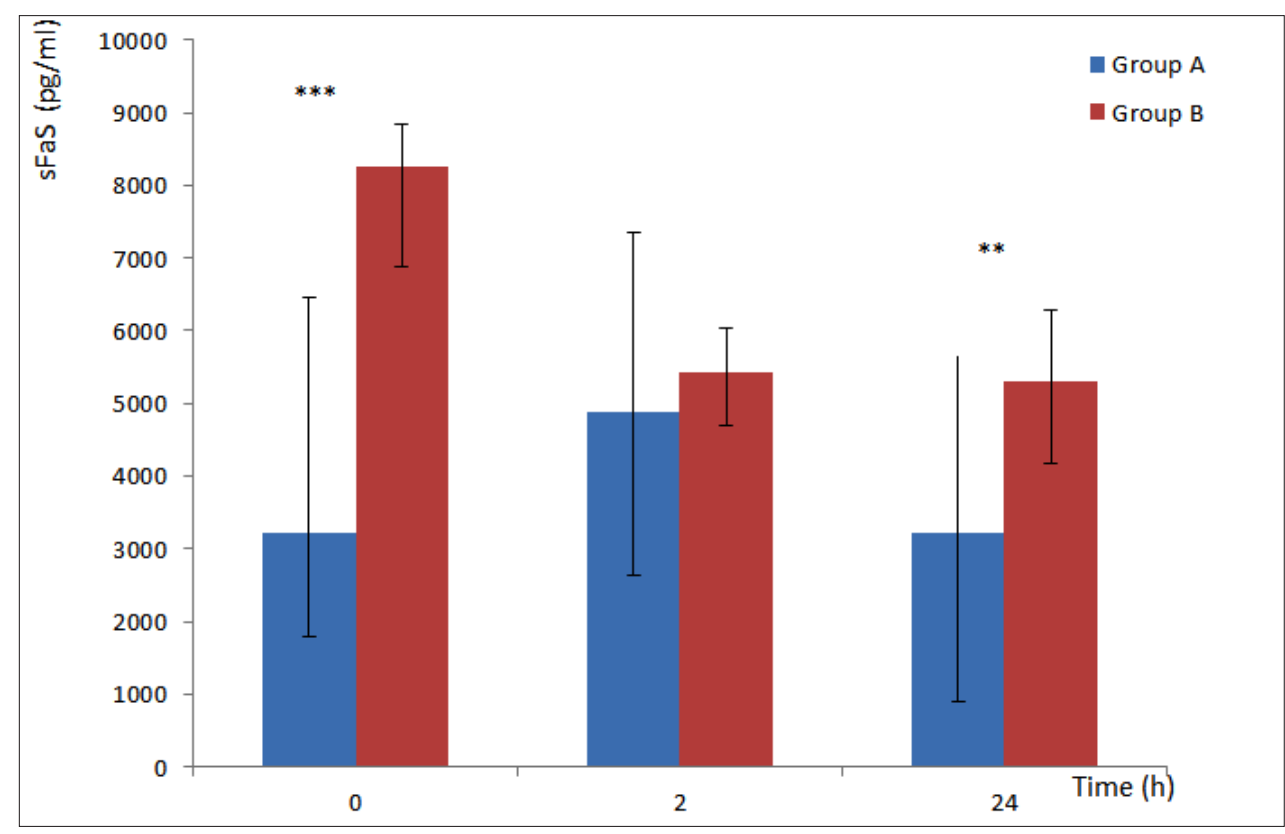

Fig. 1. The development of pleural fluid in Groups A and B. $* * * P<0.001,{ }^{* *} P<0.01$, Ad-admission, $\mathrm{D}$ - discharge

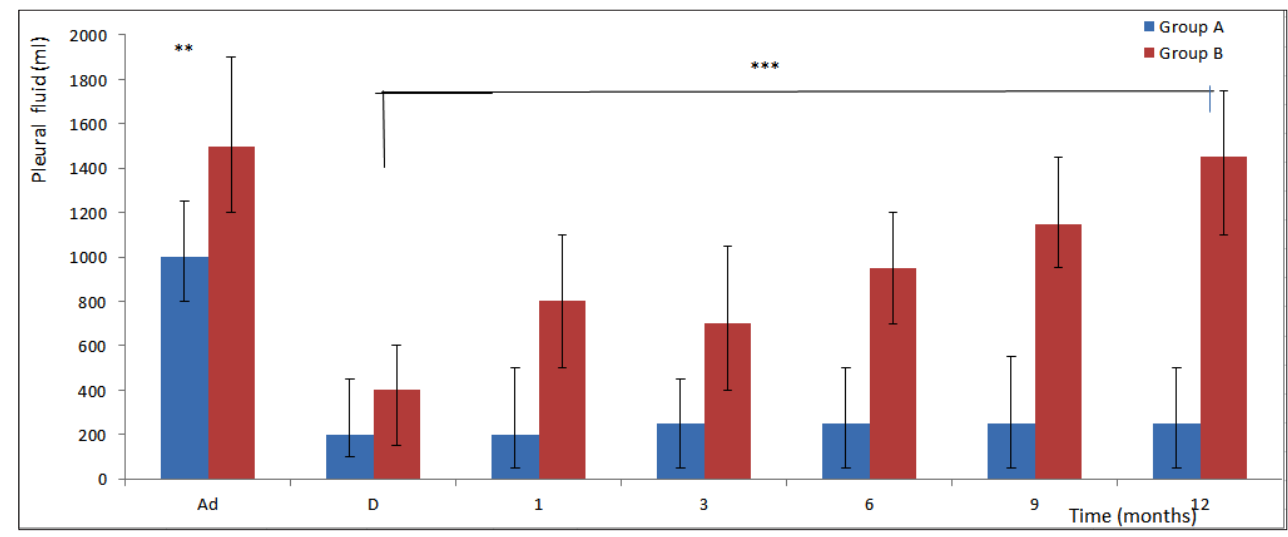

Fig. 2. Evolution of the values for sCD-163 in groups A and B. $* * * P<0.001,{ }^{*} P<0.05$

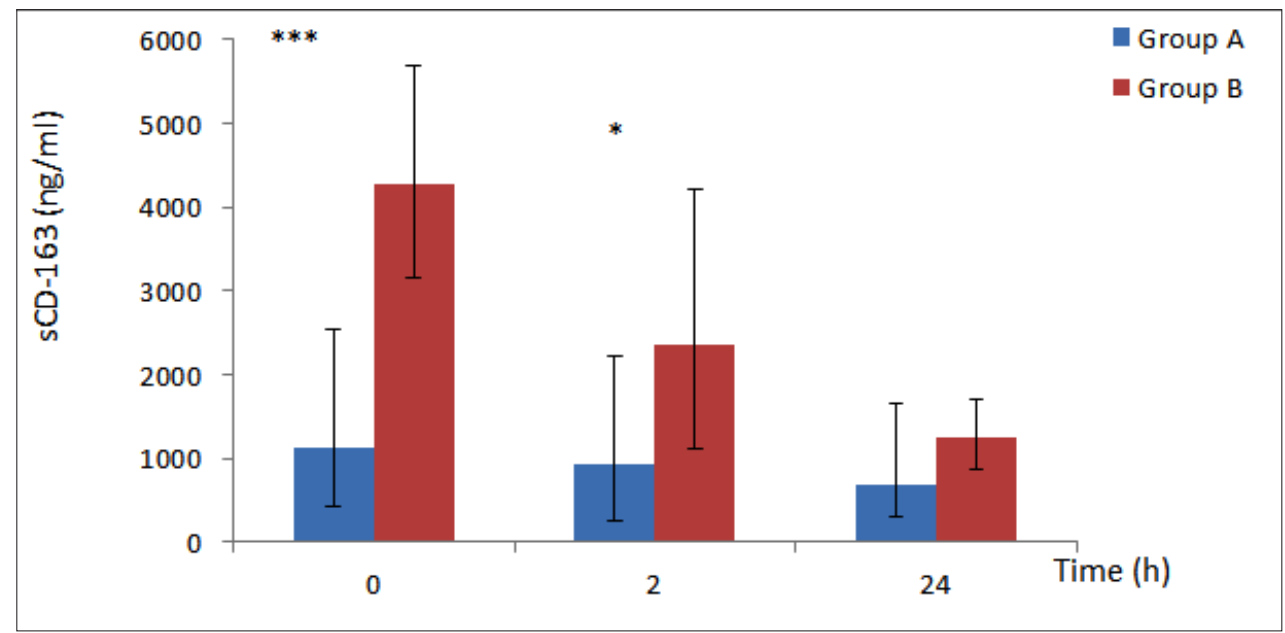

Fig. 3. Evolution of the values $\mathrm{sFaS}$ in groups $\mathrm{A}$ and $\mathrm{B}$. $* * * P<0.001, * * P<0.01$ 
Table 2. Demographic data $(\mathrm{N}=114)$.

\begin{tabular}{|c|c|c|c|}
\hline & Group A* & Group B* & $P$-value \\
\hline F (female's n (\%) & $46(40.4)$ & $7(6.1)$ & $<0.001$ \\
\hline BMI $\left(\mathrm{kg} \cdot \mathrm{m}^{-2}\right)$ & $27(23-29)$ & $26(24-30)$ & n.s. \\
\hline Thoracoscore ${ }^{* *}$ & $5.4(2.7-8.2)$ & $6.9(5.2-7.9)$ & $<0.05$ \\
\hline Volume of exsudate $(\mathrm{mL})$ & $1000 \pm 200$ & $1500 \pm 300$ & $<0.05$ \\
\hline Number of punctures & $3(2-4)$ & $5(3-5)$ & $<0.05$ \\
\hline Time of operation (min.) & $42 \pm 11$ & $46 \pm 8$ & n.s. \\
\hline Time of drainage (days) & $5 \pm 2$ & $7 \pm 4$ & $<0.05$ \\
\hline Time of hospitalization (days) & $7 \pm 2$ & $10 \pm 3$ & $<0.05$ \\
\hline$\sum \mathrm{n}(\%)$ & $98(86 \%)$ & $16(14 \%)$ & $<0.001$ \\
\hline
\end{tabular}

BMI - Body mass index, ${ }^{*}$ - median (minimum - maximum)

A - group without exudate relapsing, B - group with exudate relapsing

** - Falcoz PE et al. The Thoracic Surgery Scoring System (Thoracoscore): risk model for in-hospital death in 15,183 patients requiring thoracic surgery. J Thorac Cardiovasc Surg 2007;133(2):325-32 (ref. ${ }^{11}$ )

\section{DISCUSSION}

The presence of malignant cells in the pleural cavity is evidence that immune surveillance against cancer is failing. Very complex inflammatory body reactions preceded this event. Cancer cells and their products are identified as damage associated molecular patterns (DAMP) by innate immunity cells, especially dendritic cells. Dendritic cells contribute to the development of inflammation by production of a whole spectrum of proinflammatory cytokines such as interferons, IL-1 beta, IL-18, IL-6, TNF alpha and various chemokines. In addition, tumor antigens are processed in dendritic cells and presented to T cells. Specific T and B cell anticancer response is induced in this way. It is very likely that the inflammatory response can decelerate the tumor growth in early stages of carcinogenesis in the majority of patients. However, tumors can divert the protective immune response and paradoxically manipulate the inflammatory response to gain angiogenic support for the growth and dissemination of the cancer. There are numerous mechanisms by which tumors escape death. One example is by manipulation of apoptosis. Cancer cells develop resistance to apoptosis by induction of the antiapoptotic molecule Apo/Fas (CD95) to prevent cell apoptosis. The soluble molecule sApo/Fas can further diminish the protective immune mechanisms by binding to proaptotic membrane molecule Apo/FasL (CD178). Apo/FasL, which is upregulated on activated cytotoxic NK and $\mathrm{T}$ cells, induces apoptotic death of cancer cells after interaction with Apo/Fas complex expressed on their membranes. Binding of sApo/Fas to Apo/FasL neutralises the killing capacity of immune cells. The increased concentration of sApo/Fas in patients with poor response to talcage can be interpreted in this regard.

The manipulation of macrophages by tumor environment is well documented. Macrophages are functionally and phenotypically a very heterogenous population. At least the immunoregulatory subsets of macrophages are fully characterised. Whereas protective anticancer responses are driven by the M1 subset of macrophages, this response is dampened by alternatively activated M2c mac- rophages. M2c macrophages produce anti-inflammatory immune response reducing cytokines such as IL-10 and TGF-beta. M2 macrophages are characterised by the expression of CD163 scavenger receptor for haemoglobinhaptoglobin complexes. This molecule is easily shed into body fluids by the action of many proteases whose presence is upregulated in the tumor microenvironment. In our study, in patients who did not respond to talc-induced pleurodesis, the concentration of sCD163 molecule was highly significantly elevated in pleural exudate before talc instillation. It could be assumed from our results that in cancer patients with poor prognosis, the M2c subset of macrophages is already fully established. Elevated sCD163 level in pleural exudate of cancer patients seems to be the biomarker with predictive value in this regard.

For VTS with talcage, suitable patients should have performance status (PS) I. - II. The performance status should be determined according to Karnofsky within the range $50-70 \%$ (ref. ${ }^{12}$ ). Each surgery causes severe surgical trauma $^{13}$. The coagulation and fibrinolytic blood system is activated; the inflammatory response of the body is triggered $^{14}$. Controlled inflammatory response takes part in defence against infectious agents and it is necessary for healing the damaged tissue. The intensity of the inflammatory response depends on the type of procedure and use of foreign material. Therefore, it is stronger in surgeries using an extracorporeal circulation compared to the surgeries not involving this procedure ${ }^{15}$. In most surgeries, it is desirable to eliminate unsuitable inflammatory responses and to prevent organ impairment.

However, in some palliative surgeries the aim is to trigger the inflammatory cascade and to increase rather than suppress the effect by using a foreign substance.

In our group, the surgical burden was a constant value identical for both groups. The patients underwent the same anaesthesia, the same type of surgery and duration of procedure. Patients undergoing corticotherapy and heparin therapy were excluded from the study in order to avoid possible confounding effects on the inflammatory reaction ${ }^{16,17}$. The overall inflammatory reaction of the body is non-specific. A number of changes of the inflam- 
matory reaction of the body can be quantified, but they are not suitable for prediction of the effect of therapy due to their unspecific characteristics. Most of the maximal clinical changes in generally known inflammatory markers were found from the 3 rd day ${ }^{18}$. Following administration of talc, the measurable differences in overall inflammatory response appeared between the groups as early as after 36-48 h (ref. ${ }^{19}$ ).

Talc particules activate the mesothelium of both the visceral and parietal pleurae, resulting in production of a fibrinous exsudate which in turn induces chemical pleurodesis. Besides, mesothelial cells can take part in stabilization of febrin network by production of fibroblast growth factor enhancing further proliferation of fibrocytes ${ }^{20}$.

High concentrations both sCD163 and sApo/Fas before application of talc in this group of patients with previous unsuccessful treatment before talc administration, indicates that they could have been treated by other inflammation inducing methods. Its also important to note that there were no statistically significant differences in markers of inflammation determined in blood of both groups of patients with regard to regularly provided clinical investigations (CRP, leukocytes). Sustained local markers of antiinflammatory soluble receptors could limit talc induced inflammatory reaction in the chest cavity.

To explain the mechanism of action of talc, these particles are internalised by macrophages in several ways. On the one hand, activated macrophages are turned into the source of numerous pluripotent proinflammatory cytokines and chemokines, which further orchestrate the local inflammatory response to achieve effective pleurodesis. On the other hand, talc particle activated macrophages can succumb to apoptosis. The fate of a particular macrophage is unique, reflecting its immunobiological properties. It is well recognized that macrophages are heterogenous, At least three types of macrophages have already been identified. Of these, CD163 positive regulatory $\mathrm{M} 2 \mathrm{c}$ macrophages deserve our present attention $^{21}$

In patients who did not respond to talc-induced pleurodesis, the level of sCD163 molecule was highly significantly elevated in pleural exudate before talc instillation. It could be assumed from our results, that in cancer patients with poor prognosis, the M2c subset of macrophages is already fully established. Elevated sCD163 levels in pleural exudate of cancer patients seem to be the biomarker with predictive value in this regard. High serum levels of sApo/ Fas a sCD163 are indicative of the ability of the tumor, in a particular patient, to escape immune surveillance. Patients with high levels of sApo / Fas and sCD163 as in our study can be identified as "non-responders" as their immune system does not develop adequate reaction to talc application. However, further studies are warranted to confirm our preliminary results.

\section{CONCLUSION}

Radical surgical treatment of relapsing malignat pleural effusion is complicated by the fact that these patients have progressive tumorous disease. It is only possible to perform the highly demanding procedures such as decortication and pleurectomy in a small group of patients. In a larger group with the above criteria, there is a willingness to perform this procedure effectively with little operative risk. This is ensured by talc administration by VTS. Pleurodesis is a result of the inflammatory reaction in both pleural membranes. Successful development of the reaction depends on the overall condition and metabolic activity of the body. Sufficiently long contact of both pleural membranes is important. The production of effusion can be achieved using via other methods such as cytostatics, coloidal gold, a number of antibiotics and application of autologous blood but these are mainly the domain of oncologists. Determination of sCD163 and sApo/Fas in exudate using the ELISA method appears to be promising for the selection of patients with good treatment response to talc. High values can predict treatment failure.

Acknowledgement: Supported by the programme PRVOUK P37/4 and the MH CZ-DRO (UHHK, 00179906).

Author contributions: PH, JM: manuscript writing; NO: literature search; JK: contribution on cytometry and immunofluorescence analysis; JC: contribution on statistical analysis.

Conflict of interest statement: The authors state that there are no conflicts of interest regarding the publication of this article.

\section{REFERENCES}

1. Marel M, Zrustova M, Stastny B. The incidence of pleural effusion in a well-defined region. Epidemiologic study in central Bohemia. Chest 1993; 104:1486-9.

2. Agostini E. Mechanics of the pleural space. Physiolog Rev 1972;52:57128.

3. Agostini E, Zocchi L. Mechanical coupling and liquid exchanges in the pleural space. Clin Chest Med 1998;19:241-60.

4. de Campos JR, Vargas FS, Werebe E. Thoracoscopic Talc poudrage: a 15-year experience. Chest 2001;119(8):801-6.

5. Bennett R, Maskell N. Management of malignant pleural effusions. Curr Opin Pulm Med 2005;11:296-300.

6. Habal P, Mandák J, Štětina M. Monitorace efektivity chirurgické léčby maligních pleurálních výpotků. Klin Onkol 2010;23(2):99-103. In Czech.

7. Jankovicova K, Kondelkova K, Habal P, Krejsek J, Mandak J. TLR2 in Pleural Fluid Is Modulated by Talc Particles during Pleurodesis. Clinical and Developmental Immunology 01/2012;2012:158287. DOI:10.1155/2012/158287.

8. Krejsek J, Kuneš P, Andrýs C. Přirozená imunita, receptory pro exogenní a endogenní nebezpečné vzory v imunopatogenezi aterosklerózy. Čas Lék Čes 2005;144(2):785-9.113. In Czech.

9. Onofre G, Koláčková M, Jankovičová K. Scavenger receptor cd163 and its biological functions Acta medica (Hradec Králové) 2009;52(2):57-61.

10. Strasser A, Jost PJ, Nagata $S$. The many roles of FAS receptor signaling in the immune system. Immunity 2009;30:180-92.

11. Falcoz PE, Conti M, Brouchet $L$, Chocron S, Puyraveau M, Mercier M, Etievent JP, Dahan M. The Thoracic Surgery Scoring System 
(Thoracoscore): risk model for in-hospital death in 15,183 patients requiring thoracic surgery. J Thorac Cardiovasc Surg 2007;133(2):32532.

12. Schag CC, Heinrich RL, Ganz PA. Karnofsky performance status revisited: Reliability, validity, and guidelines. J Clin Oncology1984;2:187-90.

13. de Longu G, Moretti S, Antonucci A. Apoptosis and surgical trauma. Arch Surg 2000;135:1141-7.

14. Hornick P, Georgie A. Blood contact activation: pathophysiological effects and therapeutic approches. Perfusion 1996;11:3-19.

15. Paparella D, Yau TM, Young E. Cardiopulmonary bypass induced infammation: patophysiology and treatment. An update. Eur J Cardiothorac Surg 2002; 21:232-44.

16. Rodriguez-Panadero F, Segado A, Martin J. Activation of systemic coagulation in talc poudrage can be partially controlled with prophylactic heparin. Am J Respir Crit Care Med 1996;152:458.
17. Xie C, Teixeira LR, Wu W. The effect of corticosteroids on pleurodesis induced by doxycycline in rabbits. Chest 2002;121:216-9.

18. Shimaoka M, Hosothubo K, Sugimoto M. The influence of surgical stress on $t$ cells? Enhancement of early phase lymphocyte activation. Anesth Anal 1998;87:1431-5.

19. Habal P, Jankovicova K, Omran N, Krejsek J, Mandak J. The dynamics of selected local inflammatory markers to talc in the treatment of malignant pleural effusions. Biomed Pap Med Fac Univ Palacky Olomouc Czech Repub 2013;157(4):311-5.

20. Antony VB, Kamal MA, Godbey SW. Talc induced pleurodesis: role of a fibroblast growth factor (bFGF). Eur Respir J 1997;10:2411-8.

21. Mills ChD, Ley K. M1 and M2 macrophages: the chicken and the egg of imunity. J of Innate Immun 2014;6:716-26. 